\title{
Combined uterine and urinary bladder rupture: an unusual complication of obstructed labor in a primigravida
}

This article was published in the following Dove Press journal:

International Journal of Women's Health

21 July 2016

Number of times this article has been viewed

\author{
Idris Usman Takai' \\ Abdulkadir Abubakar ${ }^{2}$ \\ 'Department of Obstetrics and \\ Gynaecology, ${ }^{2}$ Department of Surgery, \\ Bayero University/Aminu Kano \\ Teaching Hospital, Kano, Kano State, \\ Nigeria
}

Background: Combined uterine and urinary bladder rupture following prolonged obstructed labor is indeed a momentous uro-obstetric emergency. The urinary bladder involvement is distinctly rare in the absence of factors that predispose the bladder to be adherent to the lower uterine segment and is quite unusual in a primigravida.

Objective: To report a rare case of uterine rupture involving urinary bladder secondary to a prolonged obstructed labor in a primigravida from a low resource setting.

Case: A 17-year-old married unbooked primigravida who presented with a 3-day history of spontaneous onset of labor at term that was initially managed at home and later in a primary health care center where she had fundal pressure and oxytocin augmentation, respectively. The labor was complicated by combined uterine and urinary bladder rupture with sepsis. She was resuscitated and had exploratory laparotomy with uterine and urinary bladder repair. The postoperative period was uneventful and she was followed-up at the gynecology and family planning clinics.

Conclusion: There is a need for community reawakening on the inherent risks of teenage pregnancy, bad obstetric practices, and unsupervised pregnancy, labor, and delivery, particularly in the rural settings as in the index patient. A high index of suspicion and prompt appropriate intervention will reduce the sequel of morbidity and occasional mortality from this predicament.

Keywords: uterine rupture, bladder rupture, primigravida, labor

\section{Introduction}

Uterine rupture involving the urinary bladder in labor and delivery is a momentous uro-obstetric emergency that results in stillbirth, maternal morbidity, and occasional maternal fatality. ${ }^{1}$ Uterine rupture is unusual in the primigravida. In the few isolated recorded cases of uterine rupture from prolonged obstructed labor in the primigravida, bladder rupture is distinctly rare..$^{2,3}$ We obtained a written informed consent from the patient to report this unusual intricacy of labor and delivery.

\section{Case report}

The patient was a 17-year-old unbooked primigravida who was uncertain of her date but was said to be 9 months pregnant at the time of her presentation to the Médecins Sans Frontières France (MSF-F) Emergency Obstetrics, Neonatal, and Vesico-Vaginal Fistula (VVF) Care Center in Jahun, Jigawa State, Northern Nigeria. She presented as a referral from a primary health care center (PHCC) approximately $100 \mathrm{~km}$ from Jahun town. We obtained approval from the Jigawa State Ministry of Health Ethics Committee to report these unusual complications of labor in a primigravida.
Correspondence: Abdulkadir Abubakar Department of Surgery, Bayero University/Aminu Kano Teaching Hospital, Zaria Road, Kano, PMB 3452, Kano State, Nigeria

Tel +23464803678 I4I8

Email aabdulkadir2I@gmail.com
International Journal of Women's Health 2016:8 295-298

(cc) (7) (5) 2016 Takai and Abubakar. This work is published and licensed by Dove Medical Press Limited. The full terms of this license are available at https://www.dovepress.com/terms.php cc) hereby accept the Terms. Non-commercial uses of the work are permitted without any further permission from Dove Medical Press Limited, provided the work is properly attributed. For permission for commercial use of this work, please see paragraphs 4.2 and 5 of our Terms (https://www.dovepress.com/terms.php).
for 
She was apparently well when she went into spontaneous labor 3 days prior to the presentation. The labor was under the supervision of a traditional birth attendant at home for 2 days. She had oral traditional medicaments, fundal pressure, and later a "gishiri cut" (traditional genital mutilation) while at home. On the second day, the labor pain became relentless with the involvement of the whole abdomen that necessitated her presentation to a close-by PHCC. She had oxytocin augmentation with $10 \mathrm{IU}$ given as intramuscular injection and 20 IU via an intravenous fluid at the PHCC; nonetheless, her condition deteriorated with associated high-grade fever, inability to void urine, vomiting, vaginal bleeding, chest pain, and difficulty in breathing before her referral to MSF-F a day after her presentation to the PHCC.

She attained menarche at the age of 15 and had a regular menstrual pattern. She had no known comorbidity, no antecedent abdominopelvic surgery, no abdominal trauma, no history signifying previous pelvic inflammatory disease, and no history suggestive of urinary tract pathology. She was married to a 22-year-old petty trader, had no formal education, nor was she gainfully employed.

At presentation, she was acutely ill-looking, febrile (axillary temperature $39^{\circ} \mathrm{C}$ ), dehydrated, pale but anicteric. She had a height of $1.51 \mathrm{~m}$. Her pulse rate was 130 per minute, regular with moderate volume; her blood pressure was $100 / 70 \mathrm{mmHg}$, and the heart sounds were I and II only. Her respiratory rate was 36 cycles per minute but lung fields were clinically clear. The abdomen was grossly distended with Bandl's ring and symphysio-fundal height of $41 \mathrm{~cm}$. There was generalized tenderness with crepitus and guarding over the anterior abdominal wall. Fetal parts were freely felt; singleton fetus, longitudinal lie, and cephalic presentation with a descent of $3 / 5$ th. Fetal heart sounds were absent. Pelvic examination revealed a foul smelling, blood stained vulva, and vagina. There was a glaring gishiri cut. The cervix was edematous but fully dilated with offensive watery discharge. There was marked carput formation and pelvic assessment affirmed an inadequate pelvis. An indwelling urethral catheter we passed drained scanty bloody urine. A diagnosis of a ruptured uterus with urinary bladder involvement secondary to prolonged obstructed labor and sepsis in a primigravida was made.

She was resuscitated with intravenous normal saline, intravenous antibiotic, and analgesics. Her full blood count result showed leukocytosis with a packed cell volume of $26 \%$. She had normal electrolyte but elevated urea and creatinine levels that normalized following her resuscitation. The HIV and hepatitis B surface antigen tests were negative and the

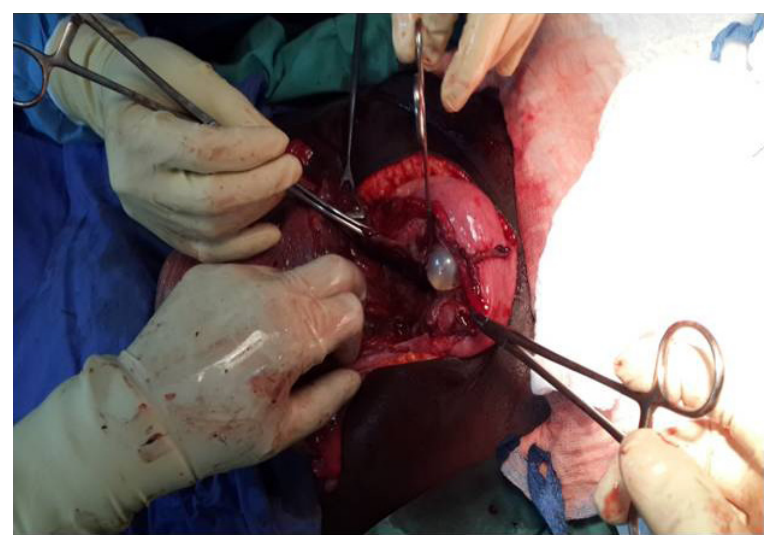

Figure I The balloon of the Foley's urethral catheter obvious through the posterior bladder wall defect deep in the pelvic after the delivery of the baby.

random blood glucose with liver function test were normal. She was prepared for exploratory laparotomy. The findings at the surgery included thick foul smelling liquor and a fresh stillborn male baby weighing $3.85 \mathrm{~kg}$. There was a ragged lower uterine segment rupture that extended down to the uterine cervix with posterior urinary bladder rupture measuring $8 \mathrm{~cm}$ and the urethral catheter balloon visible outside the bladder (Figure 1). Other pelvic and abdominal organs were normal. She had uterine and urinary bladder repair in double layers (Figures 2 and 3). Abdomen was lavaged with normal saline, cleaned, and wall sutured in layers. The estimated blood loss was $450 \mathrm{~mL}$ and she had two units of whole blood transfused. A nasogastric tube was passed and left in situ for 24 hours. She had sitz bath for the genital mutilation and was discharged home on the 12th day postoperation on hematinics after the removal of the urinary catheter. Her overall postoperative recovery period was uneventful. At her consecutive follow-up, the wound had healed completely; she was continent of urine, had no lower urinary tract symptoms, and was thereupon commenced on family planning.

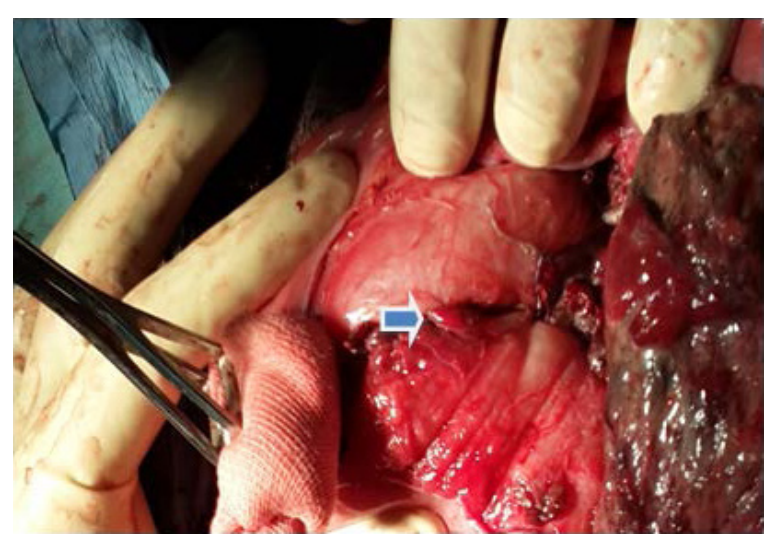

Figure 2 Repaired posterior bladder wall. 


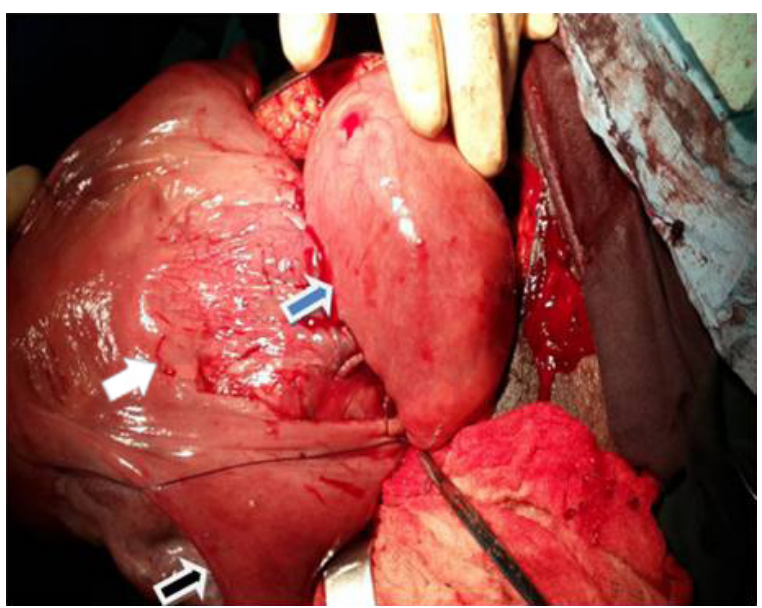

Figure 3 Repaired uterus and posterior urinary bladder wall.

Note: Black arrow on the ovary, white arrow on the uterus, and blue arrow pointing to the bladder.

\section{Discussion}

In spite of the notable global gains in health care delivery, maternal and child health has prevailed as a great health challenge in the developing countries. ${ }^{4}$ Many national and international bodies, including governmental, intergovernmental, and nongovernmental bodies, ${ }^{5}$ have devoted resources aimed at curbing the high maternal morbidity and mortality. MSF-F has been in Nigeria since 1996. In collaboration with Jigawa State Ministry of Health and indigenous specialist health caregivers, MSF-F offers free health care services in Jahun General Hospital at the maternity/VVF section since 2008. Their main objectives include bettering the access to obstetric and neonatal care, hence, lowering the maternal and neonatal mortality rates in addition to improving the care for patients with obstetric fistula. Principally, patients from the Northwest region of Nigeria and a part of Niger Republic receive care from the center. The analysis of the services offered by the center in 2013 showed that greater than $70 \%$ of the admissions were from complications of pregnancy, labor, and delivery. ${ }^{7}$

The index patient, a primigravida, presented as a referral from a PHCC approximately $100 \mathrm{~km}$ away which might have contributed to the delay in her presentation. ${ }^{8}$ The patient's prolonged obstructed labor of 3 days was further complicated by the uterine rupture involving the urinary bladder. Our literature search revealed that the Nigerian former minister of health (1961 to 1966), MA Majekodounmi, was the first known Nigerian author who reported a case of the unscarred uterine rupture with urinary bladder involvement he managed in 1954; but that patient was a multigravida. ${ }^{9}$

This is the first primigravida with combine uterine and urinary bladder rupture who presented to the MSF-F center in
Jahun and among the very few reported. Our quest of PubMed divulged a single case managed in a tertiary maternity hospital, Kathmandu, Nepal, in their 20-year review of 251 patients with a ruptured uterus. ${ }^{2}$ The urinary bladder involvement in uterine rupture is distinctly rare in the absence of adhesions of the urinary bladder to the lower uterine segment; hence, rare in the unscarred uterus ${ }^{9}$ and distinctly unusual in a primigravida. Supplementary to her delay in presentation, the index case displayed much of the harmful time-honored practices still a tradition in some of the rural settings in Nigeria. The harmful traditions included concoctions ingested during labor and delivery under the supervision of the traditional birth attendants ${ }^{10-12}$; this contributed to the index patient presenting clinical state. Pan et al reported uterine rupture in an unscarred uterus after application of fundal pressure; ${ }^{13}$ the index patient had fundal pressure while at home. Urine retention during labor is not unusual; trivial trauma or significant pressure could lead to rupture of the distended bladder in an unsupervised labor and delivery in addition to it hindering the progression of labor, as may probably be the case in our patient. Abdominal massage-related urinary bladder rupture and spontaneous rupture though rare have been reported in a distended bladder. ${ }^{14,15}$ Hence, the fundal pressure in a distended bladder could have contributed to the urinary bladder involvement as these traditional birth attendants do not have the expertise of draining the distended urinary bladder. The patient had oxytocin at the primary health care facility; these centers often have little or no experience of safe augmentation using oxytocin. Oxytocin-associated rupture of an unscarred uterus in a primigravida was recognized in the literature. ${ }^{16}$ Our patient had a total of $30 \mathrm{IU}$ of oxytocin both by intramuscular injection (an erroneous dose and route of administration) and intravenous infusion at the PHCC. The teenage pregnancy that was unbooked, the formal education she lacked, and her poor economic status are established factors that contributed to poor health-seeking behavior and a bad obstetric history along with an unfavorable outcome in our patient.

The clinical features in the patient were classical of uterine rupture with urinary bladder involvement. ${ }^{1,2,9}$ She was therefore appropriately managed as a uro-obstetric emergency by prompt resuscitation, evaluation, and laparotomy. ${ }^{1}$ At the laparotomy, the diagnosis was confirmed; cystoscopy was not done because the center does not have the facility and time was a big issue for her survival and the outcome. The stillborn is a common aftermath in uterine rupture. The patient, fortunately, had uneventful recovery before her discharge and at consecutive follow-ups. The follow-up in the patient will be all through her reproductive age. She 
was additionally counseled that her ensuing pregnancy and labor must be medically supervised and delivery should only be in a center with facility and expertise to handle high-risk deliveries.

\section{Conclusion}

Uterine rupture is not common among primigravidas and urinary bladder involvement is particularly unusual; hence, a high index of suspicion helps in the management. Prompt and appropriate intervention reduces the sequel of morbidities and occasional mortality. There is a need for continuous community reawakening on the inherent imperils of teenage pregnancy, harmful traditional obstetric practices, and those of unsupervised pregnancy, labor and delivery. Stiff legislation may enhance compliance.

\section{Disclosure}

The authors report no conflicts of interest in this work.

\section{References}

1. Chamberlain G, Steer P. ABC of labour care: obstetric emergencies. BMJ. 1999;318(7194):1342-1345.

2. Padhye SM. Rupture uterus in primigravida: morbidity and mortality. Kathmandu Univ Med J (KUMJ). 2007;5:492-496.

3. Hofmeyr GJ, Say L, Gulmezoglu AM. WHO systematic review of maternal mortality and morbidity: the prevalence of uterine rupture. BJOG. 2005;112:1221-1228.

4. World Health Organization. Maternal mortality in 1990-2015. WHO, UNICEF, UNFPA, World Bank Group, and United Nations Population Division Maternal Mortality Estimation Inter-Agency Group. Available from: www.who.int/gho/maternal_health/countries/nga.pdf?ua=1. Accessed December 27, 2015.
5. United Nations International Children's Emergency Fund. Maternal and child health. Available from: http://www.unicef.org/nigeria/ children_1926.html. Accessed December 27, 2015.

6. Médecins Sans Frontières (MSF). International Activity Report 2014. Available from: http://www.msf.org/sites/msf.org/files/msf_international_activity_report_2014_en.pdf. Accessed December 27, 2015.

7. Guerrier G, Oluyide B, Keramarou M, Grais RF. Factors associated with severe preeclampsia and eclampsia in Jahun, Nigeria. Int $J$ Womens Health. 2013;5:509-513.

8. National Statistics Directorate. Timor-Leste Demographic and Health Survey 2009-2010. Calverton: ICF Macro; 2010.

9. Majekodunmi MA. Rupture of the uterus involving the bladder. $\mathrm{Br}$ Med J. 1957;1(5013):270-271.

10. Fakeye TO, Adisa R, Musa IE. Attitude and use of herbal medicines among pregnant women in Nigeria. BMC Complement Altern Med. 2009;9:53.

11. Ologe MO, Aboyeji AP, Ijaiya MA, Adesina KT, Adewara AA, Olarinoye JK. Herbal use among pregnant mothers in Ilorin, Kwara State, Nigeria. J Obstet Gynaecol. 2008;28(7):720-721.

12. Gharoro EP, Igbafe AA. Pattern of drug use amongst antenatal patients in Benin City, Nigeria. Med Sci Monit. 2000;6(1):84-87.

13. Pan HS, Huang LW, Hwang JL, Lee CY, Tsai YL, Cheng WC. Uterine rupture in an unscarred uterus after application of fundal pressure. A case report. J Reprod Med. 2002;47(12):1044-1046.

14. Palaniappan K, Abu AP. Bladder rupture following normal vaginal delivery: A report of two cases over 11 years. Singapore J Obstet Gynaecol. 2001;32(3):78-79.

15. Faraj R, O'Donovan P, Jones A, Hill S. Spontaneous rupture of urinary bladder in second trimester of pregnancy: A case report. Aust $N Z J$ Obstet Gynaecol. 2008;10;48(5):520.

16. Catanzarite V, Cousins L, Dowling D, Daneshmand S. Oxytocinassociated rupture of an unscarred uterus in a primigravida. Obstet Gynecol. 2006;108(3 Pt 2):723-725.
International Journal of Women's Health

\section{Publish your work in this journal}

The International Journal of Women's Health is an international, peerreviewed open-access journal publishing original research, reports, editorials, reviews and commentaries on all aspects of women's healthcare including gynecology, obstetrics, and breast cancer. The manuscript management system is completely online and includes

\section{Dovepress}

a very quick and fair peer-review system, which is all easy to use Visit http://www.dovepress.com/testimonials.php to read real quotes from published authors. 